\title{
VIVÊNCIAS DE MÃES QUE TIVERAM FILHOS COM MICROCEFALIA
}

\author{
EXPERIENCES OF MOTHERS WHO \\ HAD CHILDREN WITH MICROCEPHALY
}

\section{EXPERIENCIAS DE MADRES QUE TUVIERON HIJOS CON MICROCEFALIA}

\author{
Mayra Cordeiro Oliveira ${ }^{1}$ \\ Rita de Cássia Rocha Moreira² \\ Maricélia Maia Lima ${ }^{3}$ \\ Rosana Oliveira $\mathrm{Melo}^{3}$
}

Como citar este artigo: Oliveira MC, Moreira RCR, Lima MM, Melo RO. Vivências de mães que tiveram filhos com microcefalia. Rev baiana enferm. 2018;32:e26350.

Objetivo: compreender as vivências de mães que tiveram filhos com microcefalia. Método: estudo qualitativo realizado com oito mulheres, maiores de 18 anos. Foi aplicada a técnica da entrevista semiestruturada em abril de 2017. Para a análise dos dados, utilizou-se a técnica de análise de conteúdo. Resultados: emergiram três categorias analíticas: a vivência do diagnóstico da microcefalia: ótica de mães; encontros e (des)encontros dos pais e da família no cuidado à criança com microcefalia; aprendizado com os desafios da microcefalia. As falas revelaram a força de vontade e a determinação das mães no enfrentamento das dificuldades, apesar da vivência marcada por expressões de sofrimento e dor. Conclusão: a situação vivenciada por mães que tiveram filhos com microcefalia gera incertezas em relação ao futuro do filho, altera a dinâmica familiar, a relação do casal, o rendimento financeiro e determina a opção de abandonar o trabalho profissional para cuidar do filho.

Descritores: Mães. Microcefalia. Cuidado da Criança. Zika Vírus.

Objective: understand the experiences of mothers who had children with microcephaly. Method: this is a qualitative study carried out with eight women aged 18 years and older. The semi-structured interview technique was applied in April 2017. For the analysis of the data, the technique of content analysis was used. Results: three analytical categories emerged: the experience of the diagnosis of microcephaly: mothers' optics; encounters and disagreements of the parents and the family in the care of the child with microcephaly; learning with the challenges of microcephaly. The speeches revealed the willpower and determination of the mothers in facing the difficulties, despite the experience marked by expressions of suffering and pain. Conclusion: the situation experienced by mothers who had children with microcephaly generates uncertainties regarding the future of the child, changes the family dynamics, the relationship of the couple, and the income, and defines the option to abandon the professional work to take care of the child.

Descriptors: Mothers. Microcephaly. Child Care. Zika Virus.

Objetivo: comprender las experiencias de las madres que tuvieron hijos con microcefalia. Método: estudio cualitativo realizado con ocho mujeres, mayores de 18 años. Se aplicó la técnica de entrevista semiestructurada en abril de 2017. Para analizar los datos, se utilizó la técnica de análisis de contenido. Resultados: emergieron tres categorías

\footnotetext{
Enfermeira. Universidade Estadual de Feira de Santana. Feira de Santana. Bahia. Brasil.mayra-cordeiro@hotmail.com

Enfermeira. Doutora em Enfermagem. Professora Adjunto da Universidade Estadual de Feira de Santana. Feira de Santana. Bahia. Brasil.

Enfermeira. Mestre em Enfermagem. Professora Assistente da Universidade Estadual de Feira de Santana. Feira de Santana, Bahia, Brasil.
} 
analiticas: la experiencia del diagnóstico de microcefalia: punto de vista de las madres; encuentros y (des)encuentros de los padres y de la familia en el cuidado del niño con microcefalia; aprendizaje con los desafios de la microcefalia. Los relatos revelaron la fuerza de voluntad y la determinación de las madres al enfrentar las dificultades, a pesar de la experiencia marcada por expresiones de sufrimiento y dolor. Conclusión: La situación vivida por las madres que tuvieron hijos con microcefalia genera incertidumbres relacionadas al futuro del hijo, altera la dinámica familiar, la relación de la pareja, el rendimiento financiero y determina la opción de abandonar el trabajo profesional para cuidar al hijo.

Descriptores: Madres. Microcefalia. Cuidado del niño. Zika Virus.

\section{Introdução}

A gravidez representa um momento existencial de alegria no âmbito familiar. Quando se recebe a notícia da possibilidade da chegada de um novo membro, criam-se muitas expectativas com relação a esse novo ser. Entretanto, essa alegria familiar pode dar lugar a sentimentos como medo e insegurança, diante do diagnóstico de malformação e consequente deficiência do bebê $\hat{(1)}^{\text {. }}$.

A Lei n. 13.146, de 6 de julho de 2015, conhecida como Estatuto da Pessoa com Deficiência, conceitua a expressão pessoa com deficiência como "[...] aquela que tem impedimento de longo prazo de natureza física, mental, intelectual ou sensorial, o qual, em interação com uma ou mais barreiras, pode obstruir sua participação plena e efetiva na sociedade em igualdade de condições com as demais pessoas"(2). Dessa forma, a discussão sobre microcefalia insere-se nesse contexto.

A infecção pelo vírus Zika no período gestacional trouxe visibilidade aos casos de microcefalia. Apesar do vírus já ser conhecido e estudado cientificamente, com relato em diversos países, pouco se conhecia sobre a sua possível teratogenicidade. A relação com a microcefalia só passou a ser estudada e investigada no Brasil depois do achado da concentração de material genético viral no tecido nervoso de natimortos acometidos pela microcefalia nas regiões afetadas ${ }^{(3)}$.

Os primeiros casos confirmados de infecção pelo vírus Zika no Brasil ocorreram em março de 2015, em Natal, capital do Rio Grande do Norte ${ }^{(4)}$, e em Camaçari, no estado da Bahia ${ }^{(5)}$. No ano de 2015, a Bahia totalizou 64.478 notificações de casos suspeitos de Zika em 296 (70,98\%) municípios do estado. Na ocasião, os dados evidenciavam um cenário de epidemia da doença, haja vista que o total de registros em todo o estado representava mais de 90\% dos casos de Zika notificados no Brasil $^{(4-5)}$.

O vírus Zika é um flavivírus da mesma família da dengue. É transmitido pelo mosquito Aedes aegypti aos seres humanos, principalmente por meio da picada do mosquito infectado. Foi isolado pela primeira vez na África, em uma fêmea do macaco Rhesus na floresta Zika, no ano de 1947. Posteriormente, foi propagando-se para a Ásia, Oceania e Américas, sendo responsável hoje por uma arbovirose emergente no mundo ${ }^{(6)}$.

Apesar de a principal via de transmissão do vírus ser por vetores, há evidências na literatura científica de que a transmissão pode ser feita também por via sexual, perinatal e transfusional $^{(7)}$. Ainda que a doença apresente-se de forma aparentemente benigna, atualmente quadros mais severos com o comprometimento do sistema nervoso em fetos de mães acometidas tem sido confirmados e registados, em especial no Brasil, o que demonstra ainda pouco conhecimento sobre essa ocorrência e a vulnerabilidade dessa patologia ${ }^{(6)}$.

A relação entre o vírus Zika e a microcefalia foi confirmada pela primeira vez no final do ano de 2015 pelo Ministério da Saúde (MS), devido à constatação do número elevado de microcefalia em regiões que apresentaram uma grande notificação de casos $\mathrm{Zika}^{(4)}$. O termo microcefalia significa desenvolvimento incompleto do crânio; é uma má-formação congênita, na qual o 
cérebro não se desenvolve completamente, tornando a cabeça pequena quando comparada ao comprimento do corpo. Ela é caracterizada por um diâmetro cefálico com dois ou mais desvios-padrões (DP) abaixo da média, além de uma reduzida produção de neurônios durante a fase embrionária, que pode ou não estar associada a alterações estruturais. Atualmente, os valores definidos para o diagnóstico de microcefalia após a mensuração do perímetro cefálico é de 31 ,9 centímetros para meninos e 31,5 centímetros para meninas $^{(3)}$.

As causas da microcefalia podem estar associadas a diversos fatores, como desnutrição, toxicidade, uso de drogas e infecções durante a gestação. Diversas síndromes metabólicas e genéticas, assim como agressões ambientais podem afetar o desenvolvimento do cérebro, causando distúrbios mentais. Entretanto, devido ao grande número de neonatos identificados com microcefalia em regiões com numerosos índices do surto pelo vírus Zika, e também à constatação de que esse vírus pode ultrapassar a barreira placentária e infectar o feto no útero, em especial no primeiro trimestre, estudos estão cada vez mais sendo realizados, a fim de compreender melhor como ocorre essa transmissão, em qual fase gestacional a mulher está mais vulnerável a transmiti-lo ao feto e quais outras malformações, além da microcefalia, esse vírus pode causar ao neonato ${ }^{(7)}$.

Em Feira de Santana, Bahia, os primeiros casos suspeitos de infecção pelo vírus Zika foram notificados a partir de março de 2015, ocasião em que a doença foi equivocadamente diagnosticada como dengue ou chikungunya, por conta da semelhança clínica entre essas doenças, bem como pela transmissão simultânea dessas arboviroses no município. Dados da Vigilância Epidemiológica (VE) municipal demonstram um total de 1.497 casos suspeitos de Zika em 2015, 325 casos em 2016 e 204 casos em 2017 com predominância na faixa etária de 20 a 49 anos no período. Em relação aos casos de microcefalia em recém-nascidos, possivelmente associados à infecção congênita pelo vírus Zika, até dezembro de 2017 foram notificados 58 casos suspeitos, sendo 23 confirmados, 27 descartados, 3 sob investigação e 5 que evoluíram para óbito ${ }^{(8)}$.

Portanto, diante da complexidade do problema e da experiência de vivenciar junto aos profissionais de saúde e mães de bebês com microcefalia uma situação grave e ainda desconhecida, o presente estudo suscitou a necessidade de responder a seguinte questão: Como tem sido as vivências de mães que tiveram filhos com microcefalia no município de Feira de Santana, Bahia? Foi definido como objetivo compreender as vivências de mães que tiveram filhos com microcefalia.

\section{Método}

Estudo exploratório, com abordagem qualitativa e descritiva, desenvolvido na Secretaria Municipal de Saúde (SMS), especificamente na Vigilância Epidemiológica (VE), do município de Feira de Santana, Bahia, onde iniciou o atendimento às crianças e atualmente funciona $\mathrm{o}$ acompanhamento às mães que tiveram o diagnóstico de filhos com microcefalia.

Participaram do estudo oito mulheres maiores de 18 anos, que tiveram o diagnóstico clínico epidemiológico de infecção pelo vírus Zika durante a gestação e estão sendo acompanhadas pela VE do município de Feira de Santana (BA), com consequente nascimento de crianças com microcefalia.

Por se tratar de um estudo qualitativo, a quantidade de participantes não precisou ser definida a priori, mas sim os significados atribuídos às suas falas ${ }^{(9)}$. Neste estudo, por questões de atendimento ao Sistema de Cadastro Nacional - Plataforma Brasil, foram selecionadas inicialmente dez mulheres. Entretanto, no transcorrer da coleta e análise dos dados, com algumas limitações, observou-se que o objetivo da pesquisa foi atingido com o depoimento de oito mulheres pelo critério de saturação de dados.

Para evitar subjetivação de análise, foram seguidos oito passos para processar a saturação teórica: disponibilizar os registros de dados brutos; imergir em cada registro; compilar as análises individuais; reunir os temas ou tipos 
de enunciados para cada pré-categoria ou nova categoria; nominar os dados; alocar os temas e tipos de enunciados; constatar a saturação teórica para cada pré-categoria ou nova categoria e visualizar a saturação ${ }^{(10)}$.

O primeiro passo recomenda que, além das transcrições integrais dos diálogos gravados, sejam disponibilizados arquivos digitais com as gravações de áudio para o processo de interpretação. No passo seguinte, são apreendidos cada um deles. O terceiro, orienta a compilação de enunciados captados nas falas. Como quarto passo, para cada categoria, são agrupados os enunciados identificados com os respectivos trechos das entrevistas que os descrevem. O quinto, trata-se da nominação dos dados que representam o conjunto de ideias, expressões e sentimentos que englobam as manifestações dos participantes, de modo levar a compreensão do objeto estudado, pelo pesquisador. O sexto passo é a alocação de dados para permitir a visualização dos elementos analíticos. O sétimo, busca constatar a saturação teórica, por meio de uma dinâmica de tratamento e análise dos dados, caracterizando a interrupção de novos participantes, constatando a robustez teórica pretendida, com base nos dados empíricos disponíveis e na expertise analítica e interpretativa do pesquisador. Por fim, o oitavo e último passo possibilita que, por meio de elementos de representação, como quadros analíticos teoricamente bem construídos, sejam visualizadas as categorias que emergiram, constatando a saturação teórica ${ }^{(10)}$. Assim, após aplicação dos critérios de saturação adotados, a coleta de dados foi encerrada sem impactar na construção do estudo e na análise.

Foi utilizada como técnica de coleta de dados a entrevista semiestruturada. As entrevistas foram realizadas no mês de abril de 2017, gravadas com a permissão das participantes, com respeito à privacidade e manutenção do anonimato. Os nomes das depoentes foram substituídos por nomes de flores para garantir sigilo absoluto, em observância aos princípios éticos da Resolução n. 466/2012, do Conselho Nacional de Saúde (CNS). O instrumento para coleta de dados constou de um roteiro, que teve como questão norteadora: Como tem sido a sua vivência como mãe de criança com microcefalia?

A análise dos dados foi sistematizada por meio da técnica de análise de conteúdo ${ }^{(9)}$, estruturada em três fases. A primeira foi a organização dos dados, com a transcrição das entrevistas gravadas e a leitura do material empírico coletado, o que permitiu a construção das unidades de registro. Na segunda fase, de classificação dos dados, foi realizada a leitura aprofundada e repetida das entrevistas, para que fosse possível compreender sentidos e significados dos conteúdos latentes, não apenas dos conteúdos manifestos, momento no qual emergiram as categorias analíticas. Na terceira fase, que se refere à análise final, os resultados foram articulados com a fundamentação teórica, atentando-se para a questão de pesquisa e o objetivo do estudo.

A pesquisa só foi iniciada após o aceite da instituição e aprovação pelo Comitê de Ética em Pesquisa (CEP), em 3 de janeiro de 2017, da Universidade Estadual de Feira de Santana (UEFS), Parecer favorável número 1.884.681.

\section{Resultados e Discussão}

As participantes do estudo tinham entre 23 e 35 anos. Apesar de se encontrarem em idade produtiva, a maioria abdicou dos trabalhos profissionais para cuidar dos filhos. Apenas duas encontravam-se empregadas, sendo uma autônoma e a outra lavradora. Com relação à cor, três referiram ser negras, duas brancas e três pardas. Quanto à escolaridade, seis mulheres declararam possuir o $2^{\circ}$ grau completo; uma, o $2^{\circ}$ grau incompleto e uma, o $1^{\circ}$ grau incompleto.

Cinco eram casadas. No momento do estudo, três dos maridos estavam empregados, apenas um desempregado e o outro vivendo com subemprego. Duas mulheres não eram casadas e uma convivia em união estável.

No que se refere à religiosidade, cinco eram católicas e três evangélicas. A espiritualidade foi observada como uma fonte de sustentação para essas mulheres lidarem com a patologia do filho e as novas condições existenciais. 
Vivência do diagnóstico da microcefalia: ótica de mães

A chegada de um novo ser representa um momento de grande alegria e expectativa no núcleo familiar. Quando se recebe a notícia, criam-se muitas expectativas com relação à criança. Todavia, essa alegria pode dar lugar a sentimentos de insegurança e incerteza, diante do diagnóstico do nascimento de uma criança com algum tipo de patologia ${ }^{(1)}$.

Nesse sentido, ao se depararem com a realidade do nascimento de um filho com alguma deficiência, as mães experimentam, no primeiro momento, a sensação de perda do filho idealizado e vivenciam o "luto". No entanto, um acompanhamento profissional especializado favorece a um comportamento de superação, saindo do luto à luta ${ }^{(11)}$. Desta forma, a maneira como o profissional realiza a comunicação deve ser bem planejada. Frequentemente, a notícia pode não ser transmitida de maneira adequada, o que amplia o sofrimento familiar e, consequentemente, aumenta a dificuldade em aceitar o filho. Algumas vezes, a postura distante e impessoal dos profissionais de saúde pode causar desespero e medo nos pais, como relata a fala a seguir:

[...] e o jeito que me deram a notícia. O pediatra, no caso, não chamou uma psicóloga, não esperou nem passar o efeito da anestesia. Ele invadiu a enfermaria, perguntou quem era [...] e disse: "Olha, seu filho tem microcefalia!" [...] Quando eu recebi o diagnóstico, eu pensei: minha vida agora acabou! Minha vida agora vai ser só para ele. (Lírio).

O momento do diagnóstico de qualquer doença envolve inúmeras situações, dificuldades, sentimentos e emoções que podem se agravar, a depender de como os profissionais acolhem a família e comunicam as informações sobre a criança. A chegada de uma criança com patologia no núcleo familiar pode gerar situações complexas, devido à falta de preparo e de informações adequadas para lidar com os sentimentos que surgirão nesse momento ${ }^{(1)}$. Foi possivel observar, neste estudo, que a notícia do diagnóstico não foi comunicada de maneira adequada, o que aumentou o sofrimento das mães e dos familiares, dificultando a aceitação da criança.

Sentimentos e reações de choque, tristeza, luto, medo e negação são frequentes nesse momento. Além disso, quando a família recebe a notícia da doença, passa por uma fase de desespero e transição pelo luto do filho desejado e idealizado. No entanto, no momento em que os pais começam a aceitar seus filhos, passam a amá-los e inclú́-los na família e na sociedade. Essa aceitação, leva-os a superar o preconceito e adquirir mais poder para enfrentar a situação ${ }^{(12)}$.

\footnotetext{
No momento, eu me desesperei, porque na gravidez eu não esperava, e quando ele nasceu eu recebi a notícia [...] Eu não queria aceitar. Eu me perguntava o porquê que isso aconteceu comigo. (Rosa).

Aí o marido que estava na sala pirou na bora. Eu desesperei, fiz milhões de perguntas. Ai vim para casa, minha mãe perguntou o que tinha acontecido. Ai eu dei uma surtada e comecei a chorar. (Gardênia).
}

O conhecimento da deficiência do filho e as perdas decorrentes do diagnóstico podem desencadear um estado de depressão materna, que poderá levar a mãe ao afastamento de seu filho $^{(13)}$.

Aí quando a gente descobriu, tomou aquele baque, o pai tomou aquele susto! [...] Ai, com isso, eu entrei numa depressão profunda. Não tinha ânimo para nada, para cuidar do meu filho, não saía de casa. (Íris).

A forma como é relatada uma situação clínica pode modificar as reações da mãe, o que poderá afetar o vínculo da família com a criança e gerar expectativas que influenciarão na aceitação da deficiência. Além disso, existem casos em que, devido ao despreparo, o profissional acaba dando informações equivocadas e inseguras à mãe, o que a leva a desesperar-se cada vez mais frente ao diagnóstico ${ }^{(1)}$.

Eu parei de comprar o enxoval porque, no dia que eu saí de Dr. [...], ele não me deu esperança nenbuma e o médico que me acompanhou usou essas palavras: "Comadre, a gente sabe que ele não vai vingar." (Gardênia).

Por outro lado, neste estudo, foi possível encontrar profissionais humanizados, que, mesmo diante das dúvidas, tentaram dar esperança e confortar essas mães. Essa conduta representa um chamado atentivo para a efetivação da política pública de humanização de atenção à saúde, 
haja vista a defesa da integralidade e resolubilidade das demandas das pessoas que buscam atendimento no setor público.

Foi mais tranquilo, porque eu encontrei o apoio da secretaria lá do posto de saúde, do médico que me atendeu. Porque eu entrei na sala transtornada com a notícia, mas ele me confortou tanto que eu saí de lá parecendo que minha filha não tinha nada [...] e saí tão confortada porque o médico me disse tanta coisa boa. (Girassol).

Ao analisar o relato de Girassol, pode-se inferir que a característica humanizadora é uma estratégia para se desenvolver todo o processo da relação profissional de saúde-paciente. Os profissionais da área da saúde devem estar capacitados para dar a notícia do diagnóstico da deficiência para mães e pais, dado que não se tem controle dos sentimentos que podem emergir diante de um fenômeno complexo como o da deficiência ${ }^{(13)}$.

Portanto, a forma como será fornecido o diagnóstico deve ser planejada, com o objetivo de dar apoio e esclarecer as dúvidas das famílias, para que elas possam ter compreensão da doença. A sensibilidade do profissional de saúde que comunica o diagnóstico da deficiência aos pais pode ser um fator determinante para a aceitação e adaptação da família à nova realidade, diante de um filho com deficiência.

Desta forma, com a ressignificação do filho, os progenitores podem descobrir que o seu filho tem capacidades e eles podem ajudá-lo. Com isso, até encontram satisfação, prazer e orgulho neste filho ${ }^{(13)}$. Para tanto, a abordagem aos pais, no momento da notícia do diagnóstico, bem como o apoio multiprofissional nas etapas seguintes do acompanhamento dessas famílias, torna-se essencial para o empoderamento e o equilíbrio familiar.

Assim, o ideal seria que a família fosse amparada por uma equipe multiprofissional, preparada para lhe oferecer apoio e informações necessárias, de forma cuidadosa, levando em conta que os pais estão fragilizados e confusos com o diagnóstico, o que significa reestabelecer uma nova estrutura familiar.
Encontros e (des)encontros de mães e família no cuidado à criança com microcefalia

Apesar de a deficiência em um membro da família gerar mudanças em toda a estrutura familiar, a importância da reestruturação encontra-se no fato de que será inicialmente na família, por meio dos relacionamentos intrafamiliares, que a criança aprenderá a conviver e a descobrir a vida e o mundo. As reações iniciais de crise na família podem, no decorrer do tempo, gerar possibilidades de ajustes nas relações familiares de forma saudável, com entendimento das diferenças, potencialidades e limites impostos pela deficiência ${ }^{(13)}$. Desta forma, a deficiência de um filho pode trazer consigo a possibilidade de ajuda mútua entre os membros da família. Esse apoio está descrito nas falas, as quais refletem a importância do papel do pai e do núcleo familiar nesse processo.

Eu liguei para men esposo, falei para ele sobre a microcefalia. Ele me disse assim: "Olha, do jeito que ele tiver, do jeito que for, a gente vai amá-lo de qualquer jeito." Ele me acalmou de todas as formas, e isso me confortou. (Amarílis).

Autores consideram que, "[...] para a mãe, a participação e o envolvimento do pai no cuidado da criança é fundamental para o seu equilíbrio emocional" ${ }^{(14: 50)}$. A cumplicidade do marido proporciona segurança, levando a mãe a se sentir protegida e compreendida. Ela vivencia o compartilhar de experiências e decide, em conjunto, as questões relacionadas ao filho ${ }^{(14)}$. Entretanto, nem sempre o pai e a família aceitam e apoiam a criança com deficiência. A descoberta e a vivência de ter um filho que apresenta doença congênita pode ter reflexos na vida do casal. "Os desafios impostos tanto no plano emocional, quanto no cotidiano podem levar a insatisfações, divergências de opinião e, consequentemente, atritos entre o casal" ${ }^{(15: 16)}$. O relato a seguir é ilustrativo:

Quando chegamos em casa, o pai não queria mais saber dele. Ele arrumou as coisas, foi embora e a gente se separou [...] Eu não tinha apoio de ninguém. Não tinha apoio mais dele, não tinha apoio da minha família. (Íris). 
Nesses casos, quando a mãe não recebe o apoio do marido e da família como esperava, ela busca outras referências de apoio para se sentir amparada e acolhida. O impacto de um filho com deficiência na relação conjugal já foi relatado em outros estudos. O que se observa, geralmente, é que as genitoras são as que mais se envolvem no processo de reabilitação de seus filhos $^{(13)}$. Muitas mães deste estudo encontraram esse apoio ao procurar a VE na SMS, onde profissionais e funcionários do setor abraçaram suas histórias, apoiando-as, orientando-as da melhor forma para o tratamento da criança, dando o suporte necessário para que elas buscassem força para vivenciar essa nova fase de vida, como elucida o relato a seguir:

Foi quando eu comecei a procurar a Secretaria de Saúde. Quem me deu apoio foi [...] que foram as duas que, quando cheguei aqui, que me acolheram. São duas mães para mim. Elas abraçaram minha causa junto comigo e foi ai que eu tive força para cuidar de mim e do meu filho. E assim, eu superei. (Íris).

Após o diagnóstico da deficiência, as mães modificam a sua rotina familiar, e também os hábitos de vida pessoal e profissional para atender e priorizar as necessidades do filho ${ }^{(14)}$.

De acordo com os relatos, algumas mães viam-se diante da necessidade de deixar o trabalho profissional para cuidar dos filhos. O sentimento delas é de incapacidade de levar a vida como antes da chegada do filho com deficiência. Daí começam a impor exigências no cuidado à criança.

Eu não vou dizer para você que foi fácil, porque depois que foi confirmado, e eu sai do hospital, que começou as lutas, vários exames, várias consultas [...] Eu larguei o trabalbo justamente por causa disso. Eu tive os 6 meses em casa, peguei férias, ai eu conversei no trabalbo direitinho, eles entenderam, e eu sai com todos os meus direitos [...] Eu gostava muito do meu trabalbo, muito mesmo, e você ter que abrir mão disso, porque boje eu já não posso mais, é muito difícil. (Amarílis).

As dificuldades enfrentadas por mães de crianças com deficiência, como a sobrecarga, a abdicação, o abandono, a exaustão, provocam o sofrimento diante da situação vivenciada. Além das pressões familiares com as quais têm que lidar, elas também têm que enfrentar as pressões exercidas pelas forças sociais, uma vez que a sociedade tem dificuldades de conviver com as diferenças ${ }^{(12)}$.

Ao receber a notícia, muitas mães preocupam-se com a reação das pessoas em relação ao filho com deficiência ${ }^{(16)}$. O relato a seguir é esclarecedor:

Ao receber a noticia, o que me preocupava era a reação das pessoas. Eu tinha medo das reações das pessoas, porque, querendo ou não, a gente faz e sofre o preconceito. Ele vai sofrer daqui pra frente, quando ele começar a estudar, as pessoas vão ter [...] A gente pensa que não aconteça, não é? Mas, sempre tem um ou outro que vai ter um preconceito. Eu tenho medo disso. (Rosa).

A sociedade ainda se encontra enraizada em preconceitos, com valorização apenas de indivíduos sadios, que podem produzir. Caso o indivíduo não se enquadre nesse padrão, torna-se excluído e segregado. A maneira como a criança com deficiência será aceita na família e na sociedade, dependerá, em grande parte, da atitude de aceitação da mãe $\mathrm{e}^{(12)}$. O depoimento de uma das mães expressa esse preconceito:

Então, quando eu superei meu preconceito, porque no início eu não aceitava também, foi quando a sociedade me acolheu, quando a Secretaria me acolheu [...] Então eu tive que quebrar o meu preconceito, para que as pessoas lá fora quebrassem também. (Íris).

Neste estudo, foi apreendido que, mesmo com todas as dificuldades encontradas, essas mães fortaleceram-se psicologicamente, enfrentando momentos de dor e de dificuldades vivenciadas junto ao filho com microcefalia, superando barreiras e incluindo-os na sociedade. Quando a criança com deficiência deixa de ser compreendida pelo seu déficit e passa a ser percebida como uma pessoa integral pelos pais, decorrem, desse novo olhar, atitudes e posturas que possibilitarão o seu desenvolvimento ${ }^{(14)}$.

O impacto do diagnóstico, a necessidade de adaptação à nova situação e também o estigma social podem produzir sobrecarga, conflitos e medo, o que pode comprometer a capacidade de cuidar do filho com deficiência. Apesar de alguns avanços na sociedade em relação à maneira de reagir diante das pessoas com malformação, ainda existem tabus. É preciso que haja estudos e discussões que possam ajudar, principalmente, as famílias a entenderem e conviverem com as 
malformações e deficiências que produzem limitações nas pessoas afetadas.

\section{Aprendizado com os desafios da microcefalia}

A presença de um filho com deficiência na vida da mãe e da família pode alterar rotinas e estilos, por ser um acontecimento novo. Também pode ser percebida como uma situação nova, traumática, difícil, sofrida, provocando conflitos internos e desenvolvendo sentimentos semelhantes aos vivenciados em um processo de luto. Neste sentido, a superação da notícia sobre a deficiência do filho é um dos primeiros desafios a serem enfrentados pelos pais de uma criança com deficiência ${ }^{(17)}$. No relato a seguir, a reação de uma mãe diante da falta de apoio é ilustrativa:

Ai quando a gente descobriu a gente tomou aquele baque [...] Mas eu tive que me erguer, porque eu não tinha apoio de ninguém, não tinha o apoio mais dele [esposo], não tinha o apoio da minha familia. Tinha que correr atrás das coisas sozinha. (Íris).

Quando o nascimento implica na chegada de uma criança com deficiência, o casal encontra-se diante de um fator de estresse. As situações diante do novo são potencializadas, tornando os pais, em especial a mãe, mais vulneráveis, pois terão de se ajustar e adaptar-se ao novo, ao desconhecido ${ }^{(13)}$. Dessa forma, as estratégias que as mães utilizam para lidar com as situações difíceis serão responsáveis pelas transformações de adaptação à nova situação, como exemplifica o relato a seguir.

O estresse mesmo é mais da correria que é minha vida, de estar sempre correndo atrás de médico. No início, para adaptar, foi muito complicado, porque eu nunca tinha ouvido nenhum caso. Então, tudo para mim foi novo [...] Aí bate aquele cansaço, aquele desânimo, mas aí a gente pede força para Deus e começa tudo de novo [...] E com a dica de um e de outro, a gente sempre vai tentando levar as coisas da maneira correta. (Girassol).

As mães tentam encontrar formas de conviver com o que não é considerado normal pela sociedade. Elas tentam superar o sofrimento e a dor ${ }^{(12)}$. O amadurecimento diante da doença do filho representou, neste estudo, que a mãe encontrou formas de superação de limites antes inimagináveis, como declara uma depoente.

\begin{abstract}
Muita coisa mudou minha vida, eu mudei muito como mãe, minha maneira de pensar, de tratar meus outros filhos, mudou muito [...] é uma criança que me fez enxergar a vida de uma outra forma. Hoje eu consigo ter mais carinho, mais amor, mais afeto pelos meus filhos, que antes eu não tinha. (Margarida).
\end{abstract}

Elas delinearam caminhos que pudessem ser trilhados para enfrentar e se adaptar à nova situação. Neste sentido, ser mãe de um filho com deficiência pode ser uma experiência enriquecedora e de transformação pessoal ${ }^{(13)}$.

Hoje, tudo o que eu passei foi para amadurecer! Muitas
das vezes, Deus nos dá uma criança assim, para nós
aprendermos a cuidar mais de nós e da família. E de
tudo que eu passei, se teve preconceito, abandono, eu
ainda agradeço mesmo assim, porque, com isso, eu fiquei
mais forte, aprendi a valorizar o meu filho, aprendi que
a vida não é o que a gente pensa, aprendi com [...] que
a gente tem que amar a todos, não ter preconceito com
ninguém [...] Eu aprendi tudo isso. (Íris).

O fortalecimento psicológico dessas mães traduz-se na capacidade de vencer os obstáculos da vida ${ }^{(12)}$. Além desses esforços, a fé e a esperança são utilizadas também como estratégias de superação, para enfrentar as adversidades.

Tem dias que eu estou exausta, mas tem dia que eu cresço, porque eu tenho que lutar agora para futuramente ficar melhor [...] Hoje ninguém é feliz. A gente tem momentos de felicidade. Então, a gente vive em busca desses momentos e não de absorver tudo. O que eu não posso fazer, eu entrego nas mãos de Deus. (Lírio).

Após a experiência de vivenciar e superar a notícia da deficiência dos filhos, as mães relataram mudanças em suas vidas, valorizando alguns fatores e construindo novos sentimentos. Elas procuram agora viver, aproveitar os momentos agradáveis, valorizando e apoiando o seu filho no convívio com a deficiência ${ }^{(12)}$.

Eu diria para outras mães jamais desistirem. Sempre amar, porque o amor faz com que a pessoa possa reagir e mudar aquilo que acha impossivel. Sempre amar de todas as formas, não importa as dificuldades que seu filho tiver. Tem que amá-lo de qualquer forma, porque isso vai fazer com que ele cresça forte e vai nos fazer mudar, mesmo que a gente ache impossivel. (Amarílis).

O que eu diria para outras mães, é para elas não terem medo, não terem vergonha e amar sempre, acima de tudo! Porque você ter vergonha do próprio filho que você gerou, você tem que ver que ele é como qualquer outra criança. É um amor incondicional. É um amor sem limites. Eu não tenho vergonha de mostrar minha filha; quem não quer ver não olha, mas ela está aí, para dar 
na cara de quem quer, para mostrar que é superior a qualquer um. (Girassol).

Aceitar o filho deficiente possibilita a construção do vínculo mãe e filho. O filho passa, então, a ser incluído na vida familiar e social, superando os preconceitos ${ }^{(17)}$.

Dessa forma, as mães que conseguiram superar os sentimentos negativos ressignificaram suas vidas, auxiliando seus filhos no desenvolvimento físico, psíquico, social, educacional, incluindo-os na sociedade, com a possibilidade de lutar por condições de exercer a sua cidadania.

Algumas limitações foram vivenciadas na realização da pesquisa, entre elas a disponibilidade de tempo das mães para participar da entrevista pela sobrecarga de atividades. Apesar de as entrevistas terem sido realizadas no local do atendimento, as demandas de cuidado com a criança antes ou após o momento da consulta por vezes dificultou a realização das entrevistas e a frequência de sucessivos internamentos dessas crianças também contribuiu para reduzir o número de mães participantes do estudo. Vale ressaltar que, devido à dificuldade de acesso ao diagnóstico etiológico, não foi possível ter a certeza de que os casos de microcefalia foram devido à infecção pelo vírus Zika ou por outros agentes etiológicos.

\section{Conclusão}

O estudo buscou compreender as vivências de mães com filhos com microcefalia, na perspectiva de desvelar a complexidade que é vivenciar essa situação existencial. Quando ocorre o inesperado durante a gestação, como a chegada de um filho com deficiência, a informação gera nessa mulher e na família, desequilíbrio psicológico, tendo que se reorganizarem para viver esse momento tão complexo.

O nascimento de um filho com microcefalia altera a dinâmica familiar, o estilo de vida, a relação do casal, o rendimento financeiro e afeta o trabalho profissional, pois algumas mães têm que abdicar do trabalho fora de casa para prestar o cuidado integral ao filho. Além disso, diante da situação existencial, inúmeras são as incertezas em relação ao futuro desses filhos.

Contudo, percebe-se a força de vontade e a determinação dessas mães no enfrentamento das dificuldades, apesar da vivência marcada por expressões de sofrimento e dor. Nas falas das mães emerge a capacidade dessas mulheres de se adaptarem à situação e encontrarem nova forma de compreender a vida e vivenciar a maternidade. Muitas vezes, como forma de superação, buscam apoio na religiosidade, como um conforto para os momentos difíceis.

O estudo apontou que a presença de um profissional de saúde no momento do diagnóstico e prognóstico auxilia os pais nas condutas a serem adotadas, de modo a possibilitar a diminuição do medo após a descoberta da deficiência e o futuro incerto.

\section{Colaborações:}

1. concepção, projeto, análise e interpretação dos dados: Mayra Cordeiro Oliveira, Rita de Cássia Rocha Moreira, Maricélia Maia Lima e Rosana Oliveira Melo;

2. redação do artigo e revisão crítica relevante do conteúdo intelectual: Mayra Cordeiro Oliveira, Rita de Cássia Rocha Moreira e Maricélia Maia Lima;

3. aprovação final da versão a ser publicada: Mayra Cordeiro Oliveira, Rita de Cássia Rocha Moreira e Maricélia Maia Lima.

\section{Referências}

1. Lazarotto SMR, Tavares MLB. Expectativas dos pais diante do nascimento de um filho. Rev Conversatio [Internet]. 2016 [cited 2017 Apr 10];1(2):519-32. Available from: http://www.celer. com.br/revistaconversatio/edicao/02/artigo23.pdf

2. Brasil. Lei n. 13.146, de 6 de julho de 2015. Institui a Lei Brasileira de Inclusão da Pessoa com Deficiência (Estatuto da Pessoa com Deficiência). Brasília; 2015 [cited 2017 Apr 10]. Available from: http://www.planalto.gov.br/ccivil_03/_ato20152018/2015/lei/113146.htm

3. Brasil. Ministério da Saúde. Secretaria de Vigilância em Saúde. Protocolo de vigilância e resposta à 
ocorrência de microcefalia e/ou alterações do sistema nervoso central (SNC). 2a versão. Brasília; 2016.

4. Zanluca C, Melo VCA, Mosimann ALP, Santos GIV, Santos CND, Luz K. First report of autochthonous transmission of Zika virus in Brazil. Mem Inst Oswaldo Cruz [Internet]. 2015 [cited 2017 Jan 15];110(4):569-72. Available from: http://www.scielo.br/scielo.php?script=sci_ arttext\&pid $=$ S0074-02762015000400569\&lng=en\& nrm=iso

5. Campos GS, Bandeira AC, Sardi SI. Zika vírus outbreak, Bahia, Brasil. Emerg infect dis [Internet]. 2015 [cited 2017 Jul 14];21(10):1885-6. Available from: https://wwwnc.cdc.gov/eid/article/21/10/ pdfs/15-0847.pdf

6. Vasconcelos PFC. Doença pelo vírus zika: um novo problema emergente nas Américas? Rev Pan-Amazônica saúde [Internet]. 2015 [cited 2016 Apr 28];6(2):9-10. Available from: http:// scielo.iec.pa.gov.br/scielo.php?script $=$ sci_ arttext\&pid=\$2176-62232015000200001

7. Reis RP. Aumento dos casos de microcefalia no Brasil. Rev assoc méd Minas Gerais [Internet]. 2015 [cited 2016 May 2];25(6):88-91. Available from: file://C:/Users/User/Downloads/v25s6a12.pdf

8. Bahia. Prefeitura Municipal de Feira de Santana. Vigilância Epidemiológica. Situação epidemiológica dos casos de chikungunya, dengue, vírus zika e microcefalia [Internet]. Feira de Santana; 2017 [cited 2017 May 10]. Available from: http://www. feiradesantana.ba.gov.br/sms/arq/Chikungunya_ Feira.pdf

9. Minayo MCS. O desafio do conhecimento: pesquisa qualitativa em saúde. 13a ed. São Paulo: Hucitec; 2013.

10. Fontanella BJB, Luchesi BM, Saidel MGB, Ricas J, Turato ER, Melo DG. Amostragem em pesquisas qualitativas: proposta de procedimentos para constatar saturação teórica. Cad Saúde Pública [Internet]. 2011[cited2018Nov3];27(2):388-94. Availablefrom: http:// www.scielo.br/scielo.php?script=sci_arttext\&pid=S0102311X2011000200020\&lng=en. http://dx.doi.org/10.1590/ S0102-311X2011000200020

11. Silva FJA, Gadelha MSN, Carvalho SMCR. Síndrome de Down: reação das mães frente à notícia e a repercussão na intervenção fisioterapêutica da criança. Rev Bras Ciênc Saúde [Internet]. 2017 [cited 2018 Nov 2];21:157-64. Available from: file:///C:/ Users/User/Downloads/24008-75589-1-PB.pdf

12. Guerra CS, Dias MD, Ferreira Filha MO, Andrade FB, Reichert APS, Araújo VS. Do sonho a realidade: vivência de mães de filhos com deficiência. Texto contexto enferm [Internet]. 2015 [cited 2017 Apr 27];24(2):459-66. Available from: http://www.scielo. br/pdf/tce/v24n2/pt_0104-0707-tce-24-02-00459. pdf

13. Oliveira IG, Poletto M. Vivências emocionais de mães e pais de filhos com deficiência. Rev Spagesp [Internet]. 2015 [cited 2018 Nov 4];16(2):102-19. Available from: http:// pepsic.bvsalud.org/scielo.php?script $=$ sci arttext\&pid=\$1677-29702015000200009

14. Barbosa MAM, Chaud MN, Gomes MMF. A vivência da mãe com um filho deficiente na perspectiva fenomenológica. Acta paul enferm [Internet]. 2008 [cited 2016 May 10];21(1):46-52. Available from: http://www.scielo.br/scielo.php?pid=S0103$21002008000100007 \&$ script $=$ sci_abstract\&tlng=pt

15. Silva CCB, Ramos LZ. Reações dos familiares frente à descoberta da deficiência dos filhos. Cad Ter Ocup [Internet]. 2014 [cited 2016 May 2];22(1):15-23. Available from: http://www. cadernosdeterapiaocupacional.ufscar.br/index. php/cadernos/article/view/537

16. Roecker S, Mai LD, Baggio SC, Mazzola JC, Marcon SS. A vivência de mães de bebês com malformação. Esc Anna Nery rev enferm [Internet]. 2012 [cited 2016 May 2];16(1):17-26. Available from: http://www.scielo.br/scielo.php?script=sci_ arttext\&pid=S1414-81452012000100003

17. Pinto RNM, Torquato IMB, Collet N, Reichert APS, Souza Neto VL, Saraiva AM. Autismo infantil: impacto do diagnóstico e repercussões nas relações familiares. Rev Gaúcha Enferm [Internet]. 2016 [cited 2018 Nov 2];37(3):1-9. Available from: http:// dx.doi.org/10.1590/1983- 1447.2016.03.61572

Recebido: 26 de abril de 2018 Aprovado: 6 de novembro de 2018 Publicado: 27 de dezembro de 2018 
A Revista Baiana de Enfermagem utiliza a Licença Creative Commons - Atribuição-NãoComercial 4.0 Internacional.

https://creativecommons.org/licenses/by-nc/4.0/

Este artigo é de acesso aberto distribuído sob os termos da Licença Creative Commons (CC BY-NC).

Esta licença permite que outros remixem, adaptem e criem a partir do seu trabalho para fins não comerciais. Embora os novos trabalhos tenham de lhe atribuir o devido crédito e não possam ser usados para fins comerciais, os usuários não têm de licenciar esses trabalhos derivados sob os mesmos termos. 